\title{
Tolerância à dessecação e armazenamento em temperatura sub-zero de sementes de Butia odorata (Barb. Rodr.) Noblick
}

\author{
Claudimar Sidnei Fior ${ }^{1}\left[\right.$, Samanta Siqueira de Campos $^{1}[$, Sergio Francisco Schwarz \\ 'Universidade Federal do Rio Grande do Sul, Departamento de Horticultura e Silvicultura, \\ Avenida Bento Gonçalves, 7712, 91540-000 Porto Alegre, RS, Brasil \\ *Autor para correspondência: csfior@ufrgs.br
}

Recebido em 20.VI.2019

Aceito em 18.V.2020

DOI 10.21826/2446-82312020v75e2020019

RESUMO - Butia odorata (Barb. Rodr.) Noblick é um importante recurso genético regional, porém sua propagação comercial é dificultada pela escassez de informações fitotécnicas sobre sementes e formação de mudas. O objetivo do estudo foi caracterizar o comportamento fisiológico das sementes de B. odorata, para posterior classificação fisiológica. Frutos maduros de B. odorata foram coletados e despolpados. Para a dessecação, os diásporos foram secos inteiros em estufa com temperatura constante de $30{ }^{\circ} \mathrm{C}$ por 24 horas. O armazenamento foi realizado em temperatura negativa com os diásporos embalados em saco de polietileno. Ao final de cada período foram realizados novos testes de determinação de umidade e viabilidade. Pode-se inferir que sementes de B. odorata apresentam comportamento ortodoxo, pois essas apresentaram índice de viabilidade acima de $90 \%$ com teor de água de $6,14 \%$ e armazenamento em temperatura sub-zero. Além disso, a viabilidade foi mantida em torno de $70 \%$ após armazenamento com temperatura negativa e 5\% de umidade por 32 meses.

Palavras-chave: Arecaceae, butiá, conservação ex situ, ortodoxa

\begin{abstract}
Desiccation tolerance and storage at a sub-zero temperature of Butia odorata seeds. Butia odorata (Barb. Rodr.) Noblick is an important regional genetic resource, however its commercial propagation is difficult by the shortage of plant breeding information and seedling formation. The objective of the study was to characterize the physiological behavior of $B$. odorata seeds by desiccation and conservation at different temperatures followed by viability analyses for further physiological classification. Mature fruits of $B$. odorata were collected and depulped. For desiccation, the diaspores were dried whole in an oven with a constant temperature $30^{\circ} \mathrm{C}$ for 24 hours. The storage was carried out in negative temperature with the diaspores packed in a polyethylene bag. At the end of each period, a new water content determination and the viability test were performed. It can be inferred that $B$. odorata seeds have orthodox behavior because they presented the viability index above $90 \%$ with a water content of $6.14 \%$ and storage at sub-zero temperature. In addition, viability was maintained around $70 \%$ after storage with negative temperature and $5 \%$ humidity for 32 months.
\end{abstract}

Keywords: Arecaceae, conservation ex situ, pindo palm, orthodox

\section{INTRODUÇÃO}

No Brasil são reconhecidas 296 espécies de palmeiras distribuídas em 37 gêneros da família Arecaceae. O gênero Butia apresenta 19 espécies distribuídas nas regiões Nordeste, Centro-Oeste, Sudeste e Sul nas áreas de Cerrado, Mata Atlântica e Pampa (Heiden et al. 2019. A espécie Butia odorata é nativa da região sul do Brasil e Uruguai (Noblick, 2011, Heiden et al. 2019). Os frutos, conhecidos como butiá na região sul do Brasil, são muito apreciados e possuem alto potencial, tanto para consumo in natura, como também para a produção de geleias, sucos, sorvetes, doces e licores, além da sua utilização como ornamental (Rivas \& Barbieri, 2014). Os frutos são ricos em fibras e são fontes de compostos bioativos, apresentando alta concentração de fenóis totais, vitamina $\mathrm{C}$ e carotenoides (Hoffmann et al. 2014). B. odorata é uma espécie não domesticada, propagada apenas por sementes, as quais apresentam barreiras no seu processo de germinação. As informações na literatura são incipientes em relação à conservação de sementes, superação da dormência e fenologia da espécie. Outros problemas relacionados com a espécie são a ameaça de extinção e a atividade extrativista indiscriminada de seus produtos, visto às dificuldades na produção de mudas para implantação de plantios comerciais.

A conservação de germoplasma pode ser realizada de duas formas in situ e ex situ. A conservação in situ se dá por meio da manutenção dos recursos genéticos no seu ambiente natural. A conservação ex situ é a manutenção da diversidade biológica fora do seu habitat natural. Nesse tipo de conservação incluem-se métodos como o armazenamento de sementes, bancos de germoplasma no campo, crescimento lento em óleo mineral (redução do oxigênio por uma camada de óleo que cobre a planta in vitro) e criopreservação (Edagbo et al. 2011). A conservação de sementes é considerada uma das formas mais eficientes 
e mais usadas na preservação de germoplasma ex situ de plantas, principalmente para espécies com sementes ortodoxas (José et al. 2010). O período ideal para armazenar e manter a viabilidade das sementes está diretamente relacionado com o teor de umidade associado com a temperatura em que as sementes serão conservadas (Ellis \& Roberts, 1980). Porém, o armazenamento de sementes não é aplicável a todas as espécies vegetais com a mesma eficácia, porque cada espécie possui um limite tolerável quanto à baixa umidade e temperaturas reduzidas (Rajanaidu \& Ainul, 2013).

Conforme a espécie, as sementes têm respostas fisiológicas diferentes de acordo com o conteúdo de água e a temperatura de armazenamento, por isso as sementes são classificadas em ortodoxas, recalcitrantes (Roberts, 1973) e intermediárias (Ellis et al. 1990). As sementes ortodoxas podem ser dessecadas e armazenadas com baixos teores de umidade, entre 2 e $5 \%$ e toleram o armazenamento com temperaturas abaixo de $0{ }^{\circ} \mathrm{C}$ por longos períodos (por mais de um ano), com pouca ou nenhuma perda de viabilidade (Hong \& Ellis, 2002). As sementes classificadas como recalcitrantes são dispersas com elevados teores de água, $20 \%$ a $50 \%$, não toleram a dessecação, tem uma longevidade curta, portanto, não podem ser armazenadas por longos períodos, o que dificulta sua conservação $e x$ situ. Por sua vez, as sementes intermediárias toleram a perda de água entre $10 \%$ a $12 \%$, porém, não toleram o resfriamento por longos períodos, tornando suscetíveis a lesões causadas pela temperatura (Ellis et al.1990).

Para classificar as sementes de determinada espécie quanto ao comportamento fisiológico, os testes devem levar em conta uma série de fatores para evitar conclusões equivocadas sobre resultados de análises parciais. A duração do tempo de armazenamento depende tanto dos objetivos como da espécie em estudo, pois a longevidade das sementes varia muito entre as espécies. Ela também pode variar entre os acessos de uma mesma espécie devido às diferenças do genótipo e da procedência. Esta, por sua vez, influencia pelo efeito cumulativo das condições ambientais durante a maturação das sementes, a colheita e a secagem das mesmas. O domínio do conhecimento sobre o comportamento fisiológico de sementes em condições de armazenamento é fundamental para a conservação da viabilidade (Hong \& Ellis, 1996).

Outro fator importante na classificação de sementes é o local de ocorrência natural que pode tornar variável o teor de água entre as espécies de palmeiras, pois são ambientes com diferentes condições morfoclimáticas. Por exemplo, as espécies Acrocomia aculeata e Atallea vitrivir são palmeiras nativas encontradas no Cerrado e apresentam comportamento ortodoxo (Ribeiro et al. 2012, Oliveira et al. 2016). Já as sementes da espécie Oenocarpus bacaba, encontrada na região amazônica, são sensiveis à dessecação e classifcadas como recalcitrantes (José et al. 2012).

Diante do exposto, realizou-se o presente estudo com o objetivo de caracterizar o comportamento fisiológico das sementes de Butia odorata, mediante dessecação e conservação em diferentes temperaturas, seguido de análise de viabilidade para posterior classificação fisiológica.

\section{MATERIAL E MÉTODOS}

\section{Coleta de sementes e processamento}

Frutos maduros de B. odorata foram coletados no município de Ibirubá, RS, e imediatamente despolpados manualmente. Em seguida, os diásporos foram lavados em água corrente, secos à sombra em temperatura ambiente $\left(\sim 25^{\circ} \mathrm{C}\right)$, sobre papel filtro por 24 horas, e uma amostra foi destinada para análise do teor de água. Na sequência os diásporos foram mantidos por dez dias sobre bancada de laboratório $\left(\sim 21^{\circ} \mathrm{C}\right)$ em embalagem aberta e novamente submetidos à determinação do teor de água. Posteriormente, os diásporos foram armazenados em embalagem de polietileno semipermeável, em ambiente de laboratório $\left(\sim 21{ }^{\circ} \mathrm{C}\right)$. Após cinco meses foi realizado novo teste de teor de água e viabilidade, usando os métodos descritos abaixo.

\section{Teste do teor de água}

Amostras foram submetidas à determinação do teor de água dos diásporos inteiros e das sementes isoladas através da diferença do percentual da massa após secagem a 105 ${ }^{\circ} \mathrm{C}$ até peso constante (Brasil, 2009), utilizando-se três repetições de 10 gramas de diásporos ou de sementes. Para o isolamento das sementes os diásporos foram quebrados através de pressão mecânica em torno de bancada e posteriormente os fragmentos dos caroços foram separados manualmente isolando-se as sementes.

\section{Teste de viabilidade}

Devido à dificuldade e imprecisão dos testes de germinação das sementes da espécie (Fior et al. 2011), o teste de viabilidade foi realizado em parte pelo método do embrião excisado (Brasil, 2009), e em parte utilizando-se as sementes isoladas dos endocarpos, conforme abaixo especificado para cada teste, utilizando-se como substrato o meio de cultivo MS (Murashige \& Skoog, 1962) com 30 g.L. ${ }^{-1}$ de sacarose e 8 g.L ${ }^{-1}$ de ágar (Agargel $\left.{ }^{\circledR}\right) . \mathrm{O}$ pH do meio foi corrigido para 5,8 seguido de autoclavagem por 20 min a $121^{\circ} \mathrm{C}$. Após a incubação, em câmara de fluxo laminar estéril, o material foi levado para sala de crescimento sob temperatura de $25 \pm 3{ }^{\circ} \mathrm{C}$ e irradiância luminosa de $22 \mu \mathrm{mol} . \mathrm{m}^{-2} . \mathrm{s}^{-1}$, com fotoperíodo de $16 \mathrm{~h}$. As avaliações da viabilidade foram realizadas aos 13, 23, 63, 90 e 120 dias após o estabelecimento in vitro. Em cada avaliação foram computados: a germinação, utilizando-se como critério a protrusão do botão germinativo com, pelo menos, três milímetros externos à semente; e a formação de planta completa: quando visíveis a primeira folha e a raiz primária. Quando utilizado o método do embrião excisado, foram considerados germinados os embriões que apresentavam comprimento igual ou superior a duas vezes o tamanho inicial dos embriões. Foram utilizados frascos de vidro com altura e diâmetro de $80 \mathrm{~mm}$, contendo $30 \mathrm{~mL}$ de meio. 


\section{Tratamentos de dessecação e armazenamento}

Tratamento 1 - Controle: teste de viabilidade através do método de semeadura in vitro de sementes escarificadas pela abertura total da cavidade embrionária (Fior et al. 2011). Tratamento 2 - Dessecação: secagem dos diásporos inteiros em estufa com circulação de ar forçado, sob temperatura constante de $30^{\circ} \mathrm{C}$ por 24 horas. Ao final deste período foi realizado novo teste de determinação de umidade $\mathrm{e}$ o teste de viabilidade. Tratamento 3 - Armazenamento em temperatura negativa: uma amostra de diásporos foi embalada em saco de polietileno semipermeável e armazenada por 60 dias sob temperatura constante de $-20^{\circ} \mathrm{C}$. Em seguida, foi transferido para ambiente com temperatura aproximada de $-8{ }^{\circ} \mathrm{C}$ por mais 60 dias. Posteriormente foi realizado teste de determinação do teor de umidade e de viabilidade. O delineamento foi completamente casualizado com quatro repetições de dez sementes. Os dados foram submetidos a teste de normalidade de Kolmogorov-Smirnov e homocedasticidade de Levene. Posteriormente foram submetidos à análise de variância $(\mathrm{p}<0,05)$, complementada com teste de comparação de médias LSD de Fisher.

\section{Repetição do Tratamento 3}

Para esse trabalho foram utilizados diásporos procedentes de nove matrizes, coletados em uma mesma data, caracterizando a segunda coleta de frutos no município de Ibirubá, RS. Após a coleta os diásporos foram despolpados manualmente, e uma amostra foi submetida ao teste de teor de água e de viabilidade. Os diásporos restantes foram secos sobre papel em bancada de laboratório por uma semana e em seguida armazenados em embalagem de polietileno com temperatura de $-20^{\circ} \mathrm{C}$. Após 32 meses uma amostra desses diásporos foi utilizada para análise da viabilidade com o teste do embrião excisado. Foi utilizado delineamento experimental completamente casualizado, com oito repetições, sendo uma repetição composta por um frasco com doze embriões.

\section{RESULTADOS E DISCUSSÃO}

A umidade dos diásporos imediatamente após a coleta foi de $19 \%$, enquanto que das sementes isoladas foi de $10 \%$ na primeira coleta e $12,8 \%$ quando a análise foi refeita (segunda coleta) com diásporos oriundos de nove matrizes, evidenciando elevada umidade nos tecidos do endocarpo. Esses valores encontrados para umidade logo após a coleta podem indicar um comportamento não recalcitrante da espécie. Segundo Marcos Filho (2015) sementes recalcitrantes apresentam grau de umidade elevado, em torno de 30 a $70 \%$, no momento da dispersão dos frutos.

Após dez dias expostos ao ambiente sem controle de umidade do ar e temperatura, a umidade dos diásporos reduziu em cerca de oito pontos percentuais, enquanto que das sementes a redução foi inferior a três pontos, sendo que ambos diferiram estatisticamente da umidade no ponto de coleta. Estes índices não diferiram dos obtidos após quatro meses de armazenamento em condições não controladas, provavelmente pela relação de equilíbrio entre o potencial hídrico do diásporo e o do ambiente alcançado já nos primeiros dez dias em que foram expostos. Este equilíbrio mantém o teor de umidade em níveis relativamente estáveis, com exceção de pequenas variações provocadas pela diferença de umidade do próprio ambiente (Fig. 1).

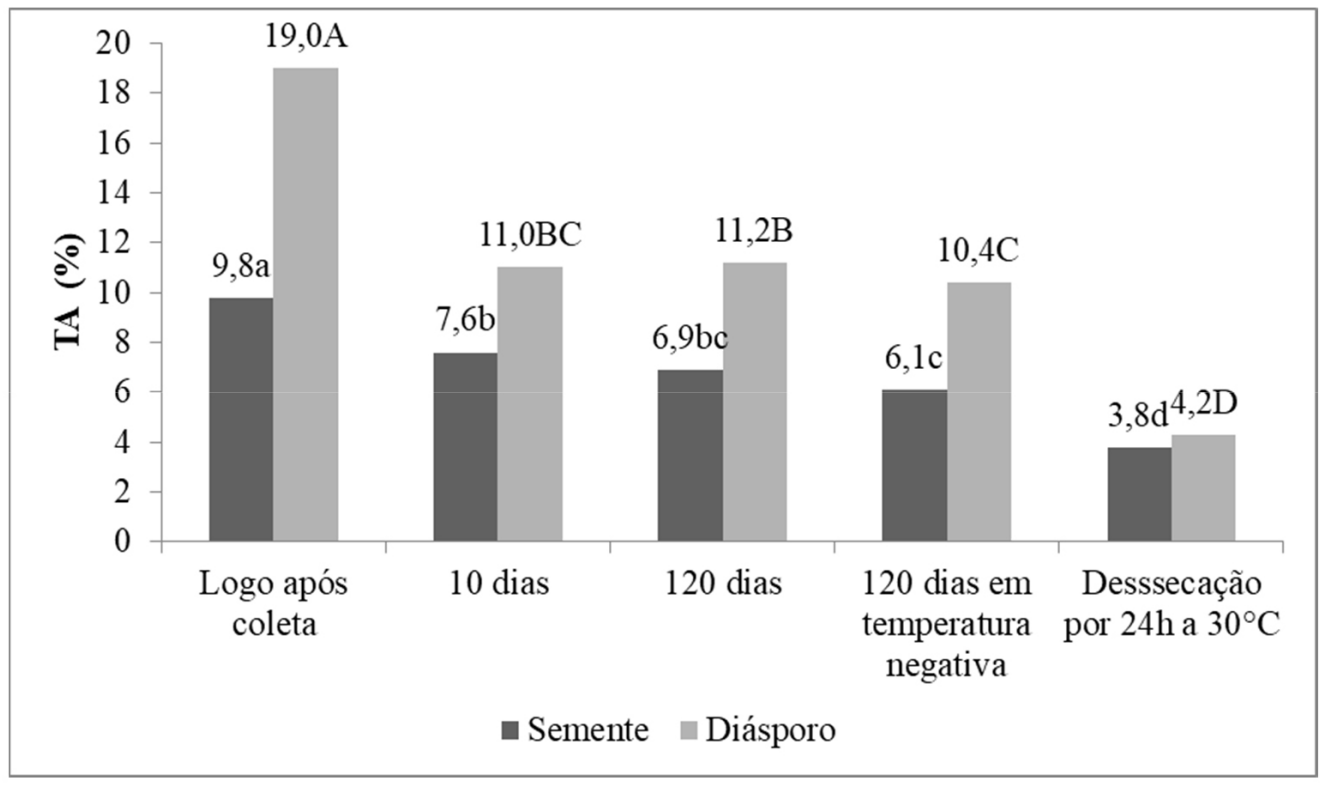

Fig. 1. Teor de água de diásporos inteiros e de sementes isoladas de Butia odorata logo após a coleta; após dez dias em ambiente de laboratório; após 120 dias; após 120 dias seguido de 120 dias sob temperatura negativa; e após 120 dias em ambiente de laboratório seguido de $24 \mathrm{~h}$ em estufa com circulação de ar forçada a $30^{\circ} \mathrm{C}$ constantes. Médias seguidas de letras minúsculas para sementes e maiúsculas para diásporos, não diferem estatisticamente pelo teste LSD de Fisher. 
$\mathrm{O}$ armazenamento em temperatura negativa provocou a redução do teor de água dos tecidos do endocarpo, mas não da semente. Possivelmente os resultados obtidos foram decorrentes do baixo potencial hídrico que ocorre em ambiente de temperatura negativa, provocando a desidratação dos tecidos do endocarpo.

A temperatura de $30{ }^{\circ} \mathrm{C}$ por 24 horas sob ventilação forçada provocou a redução do teor de água, se comparados à média das sementes de espécies florestais, mesmo as consideradas ortodoxas. Semelhante aos demais tratamentos, a redução da umidade da semente foi proporcionalmente inferior à do endocarpo, o que pode ocorrer devido à barreira física imposta pelos tecidos dessa parte do fruto em relação à semente, ou ainda ao maior percentual de lipídios nos tecidos do endosperma, se comparado aos do endocarpo, o que dificultaria a desidratação (Oliveira et al. 2013).

A germinação das sementes do tratamento controle e das armazenadas em temperatura negativa foi elevada, sem diferença estatística entre elas, o mesmo aconteceu com o percentual de plântulas completas formadas, sendo, em média, de $95 \%$ de germinação e $68 \%$ de formação de plântulas (Fig. 2).

A dessecação das sementes provocou redução significativa da viabilidade para ambas as variáveis analisadas. Ainda assim, o percentual de germinação foi relativamente elevado. Contudo, a dessecação parece ter afetado regiões específicas do embrião, inviabilizando a formação de plântulas completas, cujo percentual foi inferior a $29 \%$. Assim, pode-se inferir que a faixa de umidade crítica para sementes de $B$. odorata situa-se entre 3,8 e $6 \%$.

A porcentagem de germinação dos embriões de diásporos armazenados em temperatura sub-zero durante 32 meses, foi de $70,83 \%$ e o percentual da formação de plântulas foi de 30,44\% (Fig. 2). Esses resultados mostram que diásporos armazenados em temperaturas negativas ainda mantem as sementes viáveis com capacidade de germinar, mas a formação de plântulas completas (com folha e raiz) é afetada em parte.

Apesar de preliminares, os resultados do presente estudo sugerem que sementes de $B$. odorata, diferentemente da maioria das espécies de Arecáceas, apresentam comportamento ortodoxo. A tolerância à dessecação e $\mathrm{o}$ armazenamento em temperatura negativa por quatro meses, e aos 32 meses, não afetaram significativamente a viabilidade das sementes caracterizando esse este tipo de comportamento. $\mathrm{O}$ fato de $\mathrm{o}$ armazenamento em temperatura negativa por quatro meses, e aos 32 meses, não afetarem significativamente a viabilidade das sementes caracterizam este tipo de comportamento. Algumas sementes de espécies florestais, com $5 \%$ de umidade e após três meses de armazenamento a $-18{ }^{\circ} \mathrm{C}$ apresentaram percentual de germinação entre $67 \mathrm{e} 90 \%$ as mesmas foram classificadas como ortodoxas (Mayrinck et al. 2016). A dessecação das sementes sem a perda da viabilidade confirmaria a possibilidade desta classificação, no entanto, a redução do percentual de umidade a $3,8 \%$ pode ter sido excessiva e inviabilizou parte dos embriões. Em estudos posteriores, sugere-se que a redução da umidade pela dessecação não reduza o teor de água a menos de 5\%. Desta forma, é possível que a perda de viabilidade não ocorra como no presente trabalho, e com isso, se confirme o comportamento ortodoxo das sementes de Butia odorata. Além disso, podem ser realizados testes para verificar possíveis danos por embebição.

Há também gêneros com espécies mostrando diferentes respostas das sementes em relação ao comportamento fisiológico. Um exemplo é o de algumas palmeiras que crescem em florestas relativamente úmidas, tais como Phoenix roebelinii O'Brien e Syagrus schizophylla (Mart.) Glassman, e apresentam sementes recalcitrantes, enquanto congêneres em ambientes secos, como Phoenix rupicola Ander., P. sylvestris Roxb., P. theophrasti Gr., Syagrus botryophora (Mart.) Mart., S. flexuosa (Mart.) Becc. e $S$. yungasensis Moraes, têm sementes ortodoxas (Pritchard et al. 2004). Dickie et al. (1992) também observaram que sementes de espécies da família Arecaceae que apresentam comportamento ortodoxo são originárias de habitats secos, enquanto que as de comportamento recalcitrante são nativas de habitats relativamente úmidos. De acordo com a classificação apresentada por De Leon (1958) (citado por Costa \& Marchi, 2008), sementes de espécies de palmeiras originárias de áreas subtropicais, que apresentam estações secas e úmidas ou quentes e frias bem definidas, e sementes que apresentam o endocarpo espesso, permanecem viáveis por maior período de tempo. Essas espécies incluem os gêneros como Acrocomia Mart., Arecastrum (Drude) Becc., Attalea Kunth, Borassus L., Coccothrinax Sarg., Elaeis Jacq., Jubaea Kunth, Phoenix L., Pseudophoenix H. Wendl. ex Sarg., Rhapis L.f. ex Aiton, Sabal Adans., Syagrus Mart., Thrinax L.f. ex Sw., Trithrinax Mart., entre outros. Dias et al. (2015) concluíram que sementes de Butia capitata (Mart.) Becc. apresentam comportamento intermediário, pois as sementes armazenadas a $-18{ }^{\circ} \mathrm{C}$ perderam sua viabilidade. Comportamento oposto ao observado nos resultados obtidos neste trabalho onde, apesar de serem espécies do mesmo gênero, são originárias de habitats diferentes.

Sementes de palmeiras, em geral, não podem ser estocadas por muito tempo. Sob condições naturais, sementes de muitas espécies de Arecáceas permanecem viáveis por poucas semanas. Somente mediante condições especiais de armazenamento podem ter sua viabilidade mantida por um maior período de tempo (Robinson, 2002). Assim, pode-se inferir que sementes de Buita odorata podem ser classificadas como ortodoxas, pois essas apresentaram índice de viabilidade acima de $90 \%$ após a colheita e dessecação, seguida de armazenamento em temperatura subzero, manteve a viabilidade em torno de $70 \%$. Apesar da redução de $90 \%$ para $70 \%$ esse índice de viabilidade pode ser considerado alto para as condições de armazenamento testadas para um período de 32 meses, com temperatura negativa e com $5 \%$ de umidade. 


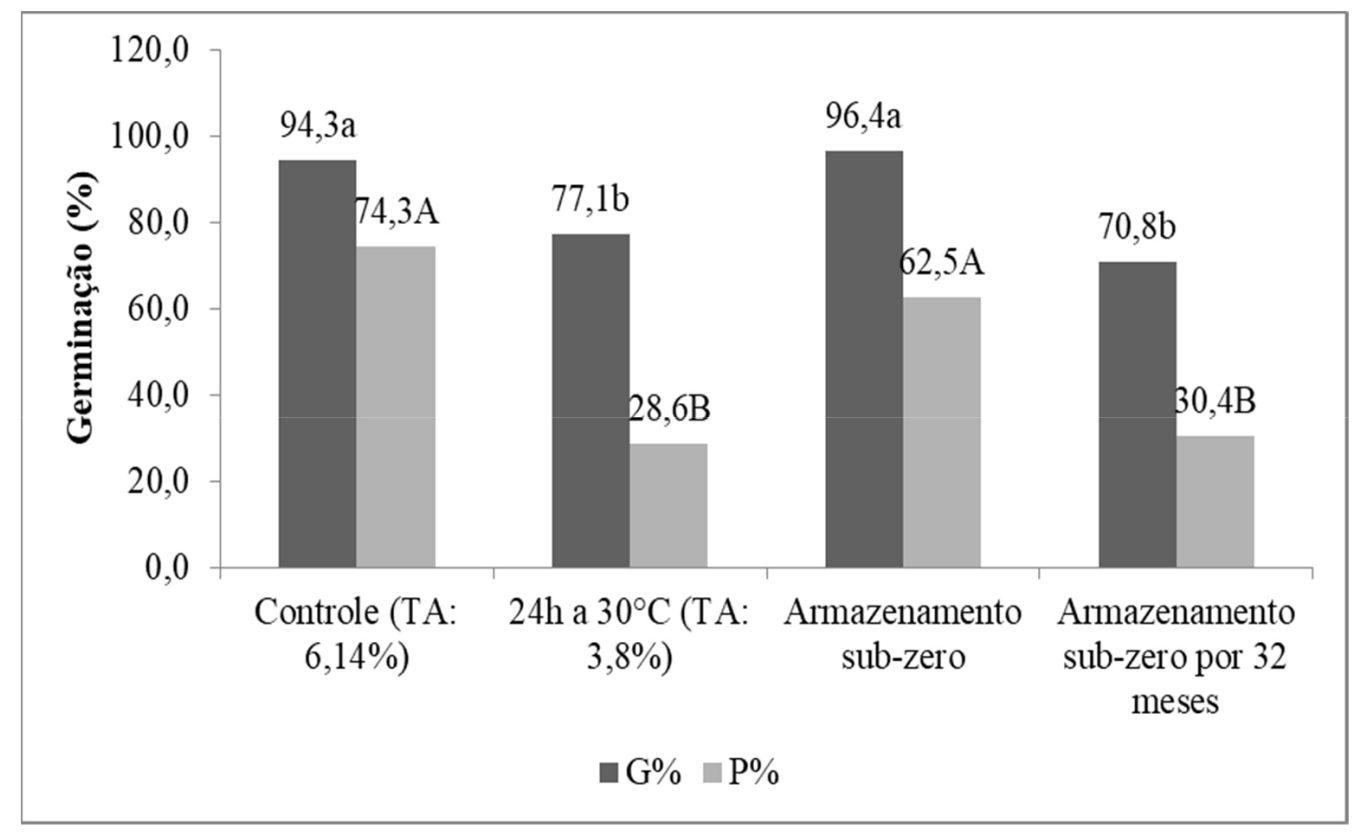

Fig. 2. Germinação (G\%) e formação de plântulas completas ( $\mathrm{P} \%)$ a partir de sementes de Butia odorata escarificadas pelo método de abertura total da cavidade embrionária, após armazenadas em ambiente de laboratório por 120 dias (teor de água de 6,14\%) (controle); após armazenadas em ambiente de laboratório por 120 dias seguido de $24 \mathrm{~h}$ em estufa com circulação de ar forçada a $30{ }^{\circ} \mathrm{C}$ constantes (teor de água de $3,8 \%$ ); e seguido de 120 dias sob temperatura negativa (sub-zero). Médias seguidas de letras minúsculas para G\% e maiúsculas para $\mathrm{P} \%$ não diferem estatisticamente pelo teste LSD de Fisher.

De acordo com as condições do presente estudo e resultados obtidos, observou-se que sementes de Butia odorata apresentam tolerância à dessecação e a armazenamento sob temperatura de $20^{\circ} \mathrm{C}$ negativos, o que sugere classificação fisiológica ortodoxa. Assim sementes de $B$. odorata podem ser armazenadas e conservadas nessas condições por período prolongado sem perder sua qualidade fisiológica.

\section{REFERÊNCIAS}

Brasil. Ministério da Agricultura, Pecuária e Desenvolvimento. 2009. Regras para análise de sementes. Mapa/ACS, Brasília. 399 p.

Costa, C.J. \& Marchi, E.C.S. 2018. Germinação de sementes de palmeiras com potencial para produção de agroenergia. Informativo ABRATES 18:39-50.

Dias, D.S., Lopes, P.S.N., Ribeiro, L.M., Oliveira, L.A.A., Mendes, E.V. \& Carvalho, V.S. 2015. Tolerance of desiccation and cryopreservation of Butia capitata palm seeds. Seed Science and Technology 43:90-100.

Dickie, J.B., Balick, M.J. \& Linington, I.M. 1992. Experimental investigations into the feasibility of ex situ preservation of palm seeds; an alternative strategy for biological conservation of this economically important plant family. Biodiversity and Conservation 1:112-119.

Edagbo, D.E., Ighere, D.A., Alowonle, A.A. \& Clement, M. 2011. Plant genetic resources: a review on the various conservation strategies to explore and the sustainable utilization of accessible germplasm. International Journal of Current Research 3:043-051.

Ellis, R.H. \& Roberts, E.H. 1980. Improved Equations for the Prediction of Seed longevity. Annals of Botany 45:13-30.

Ellis, R.H., Hong, T.D. \& Roberts, E.H. 1990. An intermediate category of seed storage behaviour I. Coffee. Journal of Experimental Botany 41:1167-74.
Fior, C.S., Rodrigues, L.R., Leonhardt, C. \& Schwarz, S.F. 2011. Superação de dormência em sementes de Butia capitata. Ciência Rural 41:1150-1153.

Heiden, G., Ellert-Pereira, P.E. \& Eslabão, M.P. Butia in Flora do Brasil 2020 em construção. Jardim Botânico do Rio de Janeiro. Disponível em: http://floradobrasil.jbrj.gov.br/reflora/floradobrasil/FB120993. Acessado em 09.03.2019.

Hoffmann, J.F., Barbieri, R.L., Rombaldi, C.V. \& Chaves, F.C. 2014. Butia spp. (Arecaceae): An overview. Scientia Horticulturae 179:122-131.

Hong, T.D. \& Ellis, R.H. 1996. A protocol to determine seed storage behaviour. International Plant Genetic Resources Institute, Roma. $55 \mathrm{p}$.

Hong, T.D. \& Ellis, R.H. 2002. Storage. In Tropical Tree Seed Manual (J.A. Vozzo, ed.). USDA Forest Service, Washington DC. p. 125-136.

José, A.C., Erasmo, E.A.L. \& Coutinho, A.B. 2012. Germinação e tolerância à dessecação de sementes de bacaba (Oenocarpus bacaba Mart.). Revista Brasileira de Sementes 34:651-657.

José, S.C.B.R. 2010. Manual de curadores de germoplasma - Vegetal: Conservação ex situ (Colbase-Sementes). Disponível em: https:// ainfo.cnptia.embrapa.br/digital/bitstream/item/149787/1/doc317. pdf. Acessado em 09.03.2019.

Marcos-Filho, J. 2015. Fisiologia de sementes de plantas cultivadas. Abrates, Londrina. 659 p.

Mayrinck, R.C., Vaz, T.A.A. \& Davide, A.C. 2016. Classificação fisiológica de sementes florestais quanto à tolerância à dessecação e ao comportamento no armazenamento. Cerne 22:85-92.

Murashige, T. \& Skoog, F. 1962. A revised medium for rapid growth and bioassays with tobacco tissue cultures. Physiologia Plantarum15:473-97.

Noblick, L.R. 2011.Validation of the Name Butia odorata. Palms 55:48-49.

Oliveira, R.A.D., Nevessa, S.C., Ribeiro, L.M., Lopes, P.S.N. \& Silvério, F.O. 2016. Storage, oil quality and cryopreservation of babassu palm seeds. Industrial Crops and Products 91:332-39.

Oliveira, N.C.C., Lopes, P.S.N., Ribeiro, L.M., Mercandante-Simões, M.O., Oliveira, L.A.A. \& Silvério, F.O. 2013. Seed structure, germination, and reserve mobilization in Butia capitata (Arecaceae). Trees 27:1633-1645. 
Pritchard, H.W., Wood, C.B., Hodges, S. \& Vautier, H.J. 2004. 100-Seed test for desiccation tolerance and germination: A case study on eight tropical palm species. Seed Science and Technology 32:393-403.

Rajanaidu, N. \& Ainul, M.M. 2013. Conservation of Oil Palm and Coconut Genetic Resources. In Conservation of Tropical Plant Species (M.N. Normah, H.F. Chin, M.R. Barbara, eds.). Springer, Nova Iorque. p. 189-212.

Ribeiro, L.M., Oliveira, T.G.S., Carvalho, V.S., Silva, P.O., Neves, S.C. \& Garcia, Q.S. 2012. The behaviour of macaw palm (Acrocomia aculeata) seeds during storage. Seed Science and Technology 40:344-353.

Rivas, M. \& Barbieri, L.R. 2014. Boas práticas de manejo para o extrativismo sustentável do Butiá. Brasília, DF: Embrapa.

Roberts, E.H. 1973. Predicting the storage life of seeds. Seed Science and Technology 1:499-514.

Robinson, M.L. 2002. Cultivated palm seed germination. Disponível em: http://www.unce.unr.edu/publications/files/ho/2002/sp0209. pdf. Acessado em 09.03.2019. 